\title{
Correction to: The method of 3D nozzle tilt cutting of abrasive water jet
}

\author{
Xiaojin Miao $^{1} \cdot$ Feng $\mathrm{Ye}^{1} \cdot$ Meiping $\mathrm{Wu}^{1} \cdot$ Lei Song $^{1} \cdot$ Zhengrong Qiang $^{1}$
}

Published online: 21 November 2019

(C) Springer-Verlag London Ltd., part of Springer Nature 2019

Correction to: The International Journal of Advanced Manufacturing Technology, Volume 103, Issue 5, pp 3109-3114 https://doi.org/10.1007/s00170-019-03757-4

Author Meiping Wuwmp169@jiangnan.edu.cn should also be declared as the corresponding author of the article https:// doi.org/10.1007/s00170-019-03757-4.

Publisher's note Springer Nature remains neutral with regard to jurisdictional claims in published maps and institutional affiliations.

The online version of the original article can be found at https://doi.org/ 10.1007/s00170-019-03757-4

\section{Xiaojin Miao}

miaoxiaojin126@126.com

$\triangle$ Meiping $\mathrm{Wu}$

wmp169@jiangnan.edu.cn

1 School of Mechanical Engineering, Jiangnan University,

Wuxi 214122, China 